\title{
Polygenic control of habitat preference and its possible role in sympatric population subdivision in an estuarine crustacean
}

\author{
MICHAEL J. STANHOPE, BRUCE J. LEIGHTON \& BRIAN HARTWICK \\ Department of Biologica/ Sciences, Simon Fraser University, Burnaby, Canada, BC V5A $1 S 6$
}

\begin{abstract}
Earlier studies of population dynamics and population genetics of an estuarine amphipod (Stanhope \& Levings, 1985; Stanhope, 1989), have suggested that amphipods residing in each of three separate and distinct habitat types within the same estuary exhibited strong habitat fidelity. These populations were separated by as little as $200 \mathrm{~m}$ of intertidal mud flat. Laboratory choice tests involving members of each population and the substrate that characterized each habitat type, demonstrated that the members of the two immediately sympatric populations (called Fucus and wood debris) exhibited strong substrate preference for their native habitat type. The third population (bank) showed a strong avoidance for a key feature of one of the habitats (Fucus) and a slight tendency to avoid the other (wood debris). Interpopulation hybrids between wood debris and bank amphipods revealed a highly significant dominance deviation in the $F_{1}$, towards wood debris preference, which disappeared in the $\mathrm{F}_{2}$. Similarly, $\mathrm{F}_{1}$ generations of crosses between Fucus and bank showed a highly significant deviation towards Fucus preference that was lost in the $\mathrm{F}_{2}$. Crosses between Fucus and wood debris amphipods showed no significant preference for either substrate in the $F_{1}$ or $F_{2}$. The results of the interpopulation crosses are interpreted as evidence for polygenic control of habitat preference with dominant genetic effects in wood debris and Fucus amphipods for their native substrate. Knowledge of when and how the wood debris arose, the nature of the original environment, as well as the ancestry of the wood debris population, provide information on shifts in habitat preference in this estuarine invertebrate and suggest habitat fidelity has been a contributing factor in sympatric population subdivision.
\end{abstract}

Keywords: amphipod, ecological genetics, estuarine, habitat preference, population subdivision, sympatric subdivision.

\section{Introduction}

Most of the theoretical and empirical studies on the role of habitat preference in population subdivision and possible sympatric speciation have concerned insects, and in particular phytophagous insects (see Tauber \& Tauber, 1989 for a recent review). An important and as yet unresolved problem is the mode of inheritance of habitat (oviposition-site) preference. Models concerned with the evolution of habitat preference and its role in sympatric population subdivision are often constructed with the assumption that habitat selection is under simple genetic control (e.g. Bush, 1974; Felsenstein, 1981; Rausher, 1984; Rice, 1984; Diehl \& Bush, 1989). Although there is a relative paucity of genetic studies, there have been a few

Correspondence: M. J. Stanhope, present address: Medical Research Building 422, 550 East Canfield Ave., Wayne State University, Detroit, MI 48201, U.S.A. which demonstrate population or strain polymorphisms in habitat preference that are clearly under polygenic control (e.g. Leslie \& Dingle, 1983 and Jaenike, 1987). Bush (1987) and Futuyma (1987) have both indicated that there is a need for more information on the mode of inheritance in order to evaluate the various models and to better understand the mechanisms behind shifts in habitat preference. Genetic studies of habitat preference in other groups of invertebrates are very poorly represented. Information regarding the genetics of habitat selection in other invertebrates could lead to more broadly applicable principles.

Substrate is known to be an important variable in structuring intertidal communities of marine invertebrates (Moore, 1975; Ricketts et al., 1985). One such group in which ecological studies of substrate preference are particularly well represented is the crustacean order Amphipoda (e.g. Fenchel \& Kolding, 
1979; Stoner, 1980; Kneib, 1982; Edgar, 1983; Oakden, 1984). Borowsky et al. (1985) reported differences in food choice in populations of a gammarid amphipod (Gammarus palustris) that were correlated with genotype: amphipods with different amylase alleles made a choice between different species of green algae. Amylase genotype is also correlated with habitat choice in another peracarid crustacean, Asellus aquaticus (Christensen, 1977). We are not aware, however, of a study which directly demonstrates a genetic basis to differences in substrate preference in any order of Crustacea.

Estuarine epibenthic amphipods are typically found on a wide range of substrates (Levings et al., 1975; Van Dolah, 1978; Borowsky et al., 1985). Eogammarus confervicolus is no exception and throughout brackish waters of the north-east Pacific, can routinely be found under various species of algae, marsh plants, wood debris and rocks (Pomeroy \& Levings, 1980; Stanhope \& Levings, 1985). Stanhope \& Levings (1985), in a study of the population dynamics of E. confervicolus, found that populations which occupy three distinct habitat types (characterized by three distinct substrate types) within the same estuary had size frequency distributions which suggested they were not experiencing any significant interhabitat immigration and emmigration and were in fact cycling independently. More recently, Stanhope (1989) has presented evidence from a genomic DNA analysis that these three populations are genetically distinct; several population specific RFLP were identified. Two of the populations are separated by only $200 \mathrm{~m}$ of intertidal mud flat, the third by approximately $1.5 \mathrm{~km}$. As part of a larger study designed to determine the factors responsible for maintaining the distinct character of these sympatric groups we have undertaken an ecological genetics study of substrate choice in this amphipod species. Knowledge of when and how one of the habitat types originated, the nature of the pre-existing habitat, as well as the ancestry of the resident population, provide information on shifts in habitat preference in this estuarine invertebrate. The results provide a comparison with those from studies of oviposition-site preference in phytophagous insects, from a dramatically different ecological situation and group of animals.

\section{Materials and methods}

\section{The habitats}

Three habitat types, characterized by three distinct substrate types, were included in this investigation: woody debris, a particular type of Fucus distichus community and embankments along the perimeter of Carex lyngbyei marshes.

Logs have been stored in estuaries throughout the north-east Pacific for 75-100 years. In areas where log rafts ground at low tide the eventual result is a mud flat devoid of macrophytes with accumulations of bark fragments in depressions along the surface. Eogammarus confervicolus can be found amongst such wood debris.

The second principal habitat type was a mixture of two brown algae: Fucus distichus and Pelvetia fastigiata (hereinafter termed Fucus) overlying soft dark black mud smelling of hydrogen sulphide. The amphipods were found within the algal mixture and at the mud surface. This algal community usually occurs as relatively small patches (rarely exceeding $1 \mathrm{ha}$ ) in estuaries or quiet, brackish water bays at about $3.5 \mathrm{~m}$ above mean low water (M. J. Stanhope, unpublished data).

Many estuaries of the north-east Pacific possess deltas covered predominantly with Carex lyngbyei. The perimeter of such a marsh is an embankment over which hangs a mat composed of sand, clay and $C$. lyngbyei rhizomes (hereinafter termed bank) at about $2.0 \mathrm{~m}$ above mean low water. Eogammarus confervicolus can be found on the underside of this mat, mixed with the rhizomes of the marsh plant.

Each of these habitat types exists in the Squamish River estuary, British Columbia, Canada (Fig. 1). Wood debris and Fucus habitats in the Squamish estuary are separated by approximately $200 \mathrm{~m}$ of intertidal mud flat whereas the distance between bank and wood debris habitats is approximately $1.5 \mathrm{~km}$, with a variety of physical obstructions in the middle of the estuary. The area of the Fucus habitat in the Squamish estuary is approximately $5000 \mathrm{~m}^{2}$, the wood debris habitat exists over an area approximately 10 times the size of the Fucus habitat. Bank habitat exists along the perimeter of the Central and East Deltas as well as along the sides of the many channels running through both deltas.

\section{Substrate choice tests}

Pairwise substrate choice tests were performed with individuals from each population and the three possible combinations of substrate. Tests were conducted in the laboratory, using a series of identical 200 litre aquaria, each with a central drain that was surrounded by fine mesh screen. The bottom of the aquarium was partitioned into four equal parts, which were used to contain the representative substrates. The wood debris substrate was simply a mixture of wood chips overlying the sand-mud typical of that habitat. Bank substrate consisted of a layer of sand, several 


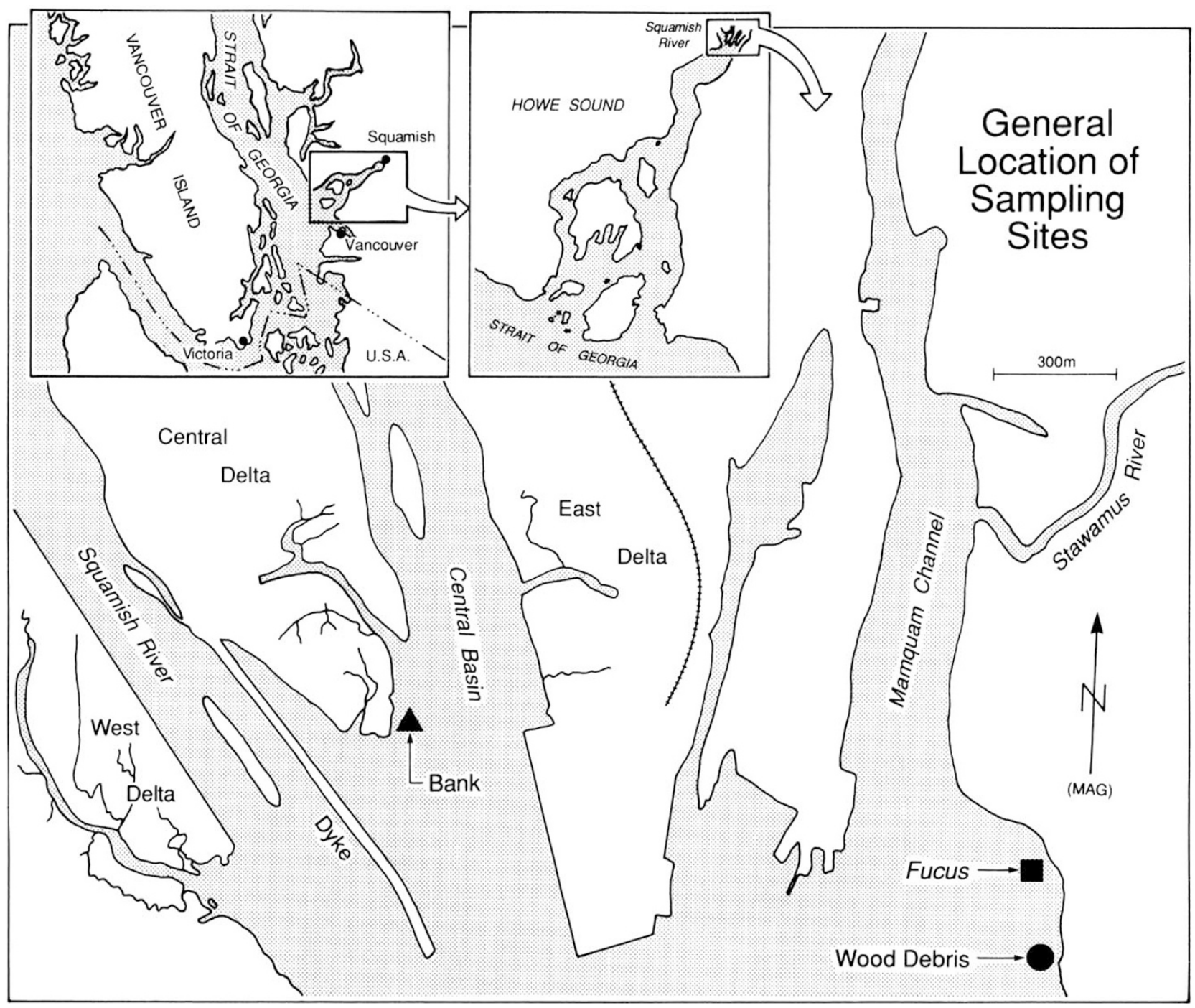

Fig. 1 Location of the Squamish estuary and a map of the estuary showing the major physical features and the position of the three principal habitat types.

pieces of the rhizome mat with additional bunches of entangled Carex rhizome. The Fucus habitat was judged to have two critical components: the algae and the $\mathrm{H}_{2} \mathrm{~S}$ mud. Tests involving Fucus were thus performed in two ways: with the algal mixture overlying a sand-mud mixture typical of the other two habitats and with the algae overlying $\mathrm{H}_{2} \mathrm{~S}$ mud. The two substrates involved in any particular test were arranged in each aquarium such that similar substrate types were contained in the compartments diagonally opposite each other. The aquaria were filled with water at $10^{\circ} \mathrm{C}$ and $10 \%$ [salinity tolerance of $E$. confervicolus is between 5 and 25 parts per thousand; optimum is between 5 and 10 parts per thousand (Sharp, 1980)]. One hundred amphipods from a particular habitat were added to the water, after $24 \mathrm{~h}$ the water was drained and the number of animals in each substrate was determined (the number of amphipods in the two compartments containing the same substrate type were pooled). Chisquare was used in analysis and because in all choice tests involving different substrate types there was a single degree of freedom, Yates correction for continuity was employed (i.e. absolute value of each deviation of observed frequency from expected frequency was reduced by 0.5 or in the case of contingency chisquare comparisons, reduced by half the total number of amphipods; Zar, 1974). Each pairwise test was repeated with different individuals on three occasions. As reproductively active individuals could possibly confound the results by choosing mates instead of substrate [waterborne pheromones, secreted by females that attract males, have been demonstrated in other 
amphipods (Borowsky, 1984, 1985)], only immature individuals were used in choice tests $(2-5 \mathrm{~mm}$ size range); test animals came directly from the Squamish estuary.

The same pairwise choice tests were performed on $F_{1}$ and $F_{2}$ generations of interpopulation hybrids. Parents for these crosses came from separating mating pairs in the respective estuarine habitats. The bank and wood debris populations are bivoltine, the Fucus population is univoltine (Stanhope \& Levings, 1985). Matings involved summer adults of bank and wood debris and the single generation from Fucus. All

Table 1 Control experiments, in which bank, wood debris and Fucus amphipods (BKSQ, WDSQ and FSQ respectively) were presented with only their native substrates (BK, WD and F respectively). Compartments 1, 3 and 2, 4 contain the same substrate, in all subsequent tests involving choice between different substrate types

\begin{tabular}{llllll}
\hline & & \multicolumn{3}{l}{$\begin{array}{l}\text { Number in each compartment } \\
\text { of the apparatus }\end{array}$} \\
\cline { 3 - 6 } Source & Substrate & 1 & 2 & 3 & 4 \\
\hline BKSQ & BK & 29 & 17 & 30 & $24 \mathrm{~ns}$ \\
& BK & 22 & 35 & 17 & $24 \mathrm{~ns}$ \\
& BK & 16 & 30 & 26 & $28 \mathrm{~ns}$ \\
WDSQ & WD & 26 & 30 & 18 & $25 \mathrm{~ns}$ \\
& WD & 38 & 16 & 22 & $22 *$ \\
FSQ & WD & 18 & 23 & 23 & $36 \mathrm{~ns}$ \\
& F & 24 & 33 & 20 & $23 \mathrm{~ns}$ \\
& F & 16 & 26 & 24 & $33 \mathrm{~ns}$ \\
& F & 35 & 19 & 22 & $22 \mathrm{~ns}$ \\
$*=0.01<P<0.05 ;$ & & & & \\
ns $=$ not significant. & & & &
\end{tabular}

crosses were reciprocal and were established using approximately 100 pairs. They were conducted in laboratory 50-litre aquaria containing bank substrate with well aerated water maintained at $10^{\circ} \mathrm{C}$ and $10 \%$ o. Females were held separately for a few weeks prior to crossing, to avoid any possible confusion due to an earlier fertilization. Tests were performed on the $2-5$ $\mathrm{mm}$ size class.

To analyse the results of the crosses, we employed a measure suggested by Wright (1978), to represent the degree to which hybrids deviate from intermediacy: $F_{1}$ or $F_{2}$ mean minus the lower parental mean/the upper minus the lower parental mean. A completely intermediate phenotype is represented by a value of 0.5 .

\section{Results}

Controls of bank, Fucus and wood debris amphipods presented with only their native substrate (Table 1) showed no preference for any particular compartment of the apparatus; replicates were heterogenous, which suggests the amphipods distributed themselves randomly and that there was no directional bias inherent in the experiment.

In experiments where amphipods were offered a choice of two different substrate types (Table 2), several very distinct preferences were apparent. Amphipods from Fucus and wood debris chose their native substrate over any other. Bank amphipods chose the rhizome mat over wood debris but showed no distinction between bank and Fucus. Both bank and wood debris amphipods avoided Fucus substrate when the algae were overlying $\mathrm{H}_{2} \mathrm{~S}$ mud; Fucus amphipods showed no preference between Fucus with $\mathrm{H}_{2} \mathrm{~S}$ mud and without. Fucus and bank amphipods avoided wood debris substrate even in situations where their native

Table 2 The substrate selection of wild caught individuals; BKSQ, WDSQ and FSQ = the Squamish bank, wood debris and Fucus populations respectively; $\mathrm{BK}, \mathrm{WD}, \mathrm{F}\left(\mathrm{H}_{2} \mathrm{~S}\right)$ and $\mathrm{F}=$ bank, wood debris, Fucus with $\mathrm{H}_{2} \mathrm{~S}$ mud and Fucus substrate respectively. Numbers in each substrate represent pooled replicates $(100$ amphipods per choice test $)$. Replicates were judged homogeneous with the exception of those experiments designated with $\mathrm{i}$ and ii; substrate choice of the individual replicates in those two cases were as follows: i: $61 / 37^{*}, 58 / 41 \mathrm{~ns}, 40 / 60 \mathrm{~ns}$; ii: $57 / 41 \mathrm{~ns}, 60 / 31^{* *}, 33 / 66^{* *}$

Substrate choices

\begin{tabular}{lllllll} 
Source & BK/WD & F/WD & BK/F & BK/F(H $\left./ H_{2} \mathrm{~S}\right)$ & F/F(H $\left.\mathrm{H}_{2} \mathrm{~S}\right)$ & WD/F(H $\mathrm{S})$ \\
\hline BKSQ & $198 / 94^{* * *}$ & $131 / 57^{* * *}$ & $\mathrm{i} 159 / 138$ & $219 / 80^{* * *}$ & $208 / 83^{* * *}$ & $169 / 130^{*}$ \\
WDSQ & $49 / 243^{* * *}$ & $10 / 286^{* * *}$ & $179 / 111^{* * *}$ & $220 / 74^{* * *}$ & $181 / 100^{* * *}$ & - \\
FSQ & $225 / 43^{* * *}$ & $268 / 28^{* * *}$ & $42 / 252^{* * *}$ & $45 / 240^{* * *}$ & ii $150 / 138$ & - \\
\hline
\end{tabular}

$*=0.01<P<0.05$;

$* *=0.001<P<0.01$;

*** $=P<0.001$;

$\mathrm{ns}=$ not significant. 
Table 3 (a) Substrate selection of the $F_{1}$ and $F_{2}$ generations of reciprocal laboratory crosses involving the Squamish bank (BKSQ) and wood debris (WDSQ) populations. Numbers in each substrate $(B K=$ bank, $W D=$ wood debris $)$ represent pooled replicates ( 100 amphipods per choice test). Replicates were judged homogeneous in all cases. Wright's measure of departure from intermediacy was applied to incidences of wood debris choice. (b) Several comparisons of bank and wood debris substrate selection between different BKSQ and WDSQ laboratory hybrids using a contingency chi-square analysis. Males are listed first in each of the crosses compared

\begin{tabular}{|c|c|c|c|c|c|}
\hline \multicolumn{2}{|l|}{$\begin{array}{l}\text { (a) } \\
\text { Parents }\end{array}$} & \multicolumn{2}{|l|}{$F_{1}$} & \multicolumn{2}{|l|}{$F_{2}$} \\
\hline & & \multirow{2}{*}{$\begin{array}{l}\text { Choice } \\
\text { BK/WD }\end{array}$} & \multirow{2}{*}{$\begin{array}{l}\text { Wright's } \\
\text { measure }\end{array}$} & \multirow{2}{*}{$\begin{array}{l}\text { Choice } \\
\text { BK/WD }\end{array}$} & \multirow{2}{*}{$\begin{array}{l}\text { Wright's } \\
\text { measure }\end{array}$} \\
\hline Male & Female & & & & \\
\hline BKSQ & BKSQ & $190 / 107^{* * *}$ & 0.00 & $212 / 84 * * *$ & 0.00 \\
\hline BKSQ & WDSQ & $68 / 223^{* * *}$ & 0.93 & $127 / 158 \mathrm{~ns}$ & 0.47 \\
\hline WDSQ & BKSQ & $49 / 249^{* * *}$ & 0.80 & $133 / 158 \mathrm{~ns}$ & 0.45 \\
\hline WDSQ & WDSQ & $36 / 240^{* * *}$ & 1.00 & $42 / 251^{* * *}$ & 1.00 \\
\hline
\end{tabular}

(b)

Contingency

Experiments compared chi-square

1. $\mathrm{BKSQ} \times \mathrm{BKSQ}\left(\mathrm{F}_{1}\right)$ vs. $\mathrm{BKSQ} \times \mathrm{WDSQ}\left(\mathrm{F}_{1}\right)$

$96.77^{* * *}$

2. $\mathrm{BKSQ} \times \mathrm{BKSQ}\left(\mathrm{F}_{1}\right)$ vs. $\mathrm{WDSQ} \times \mathrm{BKSQ}\left(\mathrm{F}_{1}\right)$

$137.85^{* * *}$

3. $\mathrm{BKSQ} \times \mathrm{WDSQ}\left(\mathrm{F}_{1}\right)$ vs. WDSQ $\times \mathrm{WDSQ}\left(\mathrm{F}_{1}\right)$

$9.40^{* *}$

4. $\mathrm{WDSQ} \times \mathrm{BKSQ}\left(\mathrm{F}_{1}\right)$ vs. WDSQ $\times \mathrm{WDSQ}\left(\mathrm{F}_{1}\right)$

$1.06 \mathrm{~ns}$

5. $\mathrm{BKSQ} \times \mathrm{WDSQ}\left(\mathrm{F}_{1}\right)$ vs. $\mathrm{BKSQ} \times \mathrm{WDSQ}\left(\mathrm{F}_{2}\right)$

$27.94^{* * *}$

6. WDSQ $\times \mathrm{BKSQ}\left(\mathrm{F}_{1}\right)$ vs. WDSQ $\times \mathrm{BKSQ}\left(\mathrm{F}_{2}\right)$

$57.68^{* * *}$

7. $\mathrm{WDSQ} \times \mathrm{WDSQ}\left(\mathrm{F}_{1}\right)$ vs. WDSQ $\times \mathrm{WDSQ}\left(\mathrm{F}_{2}\right)$

$0.11 \mathrm{~ns}$

8. $\mathrm{BKSQ} \times \mathrm{BKSQ}\left(\mathrm{F}_{1}\right)$ vs. $\mathrm{BKSQ} \times \mathrm{BKSQ}\left(\mathrm{F}_{2}\right)$

$0.57 \mathrm{~ns}$

9. $\mathrm{BKSQ} \times \mathrm{WDSQ}\left(\mathrm{F}_{1}\right)$ vs. WDSQ $\times \mathrm{BKSQ}\left(\mathrm{F}_{1}\right)$

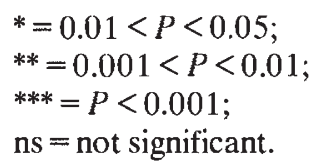

substrate was not offered as one of the choices; wood debris amphipods, in a similar experiment, avoided Fucus.

In crosses between bank and wood debris amphipods (Table 3 ) the $F_{1}$ hybrids chose wood debris over bank substrate with a frequency highly different from the bank control group (Table $3 \mathrm{a}$ and $\mathrm{b}$, comparisons 1 and 2) and very similar to that involving the wood debris control group (Table $3 a$ and $b$, comparisons 3 and 4). This nearly complete deviation towards wood debris preference disappeared in the next generation (Tables $3 \mathrm{a}$ and $\mathrm{b}$, comparisons 5 and 6 ); substrate choice was roughly intermediate between the two parental phenotypes in the $F_{2}$ (Table 3a). These results contrast sharply with those from the control crosses, in which there was no difference in substrate preference between the $F_{1}$ and $F_{2}$ (Table $3 a$ and $b$, comparisons 7 and 8). Although there was a statistically distinguish- able difference in the frequency of choice in the $F_{1}$ of reciprocal crosses (Table 3b, comparison 9), the difference was in a direction opposite to that expected if there was cytoplasmic or maternal effects.

Interpopulation $F_{1}$ hybrids of Fucus and bank, whether given a choice of bank and Fucus substrate or bank and Fucus with $\mathrm{H}_{2} \mathrm{~S}$ mud, showed a deviation towards choice of Fucus substrate (Table $4 \mathrm{a}$ and b, comparisons 1-4). The tendency to choose Fucus substrate dropped significantly in the $F_{2}$ (Table $4 a$ and b, comparisons 5 and 6 ) to a level either approximately intermediate to that exhibited by the parental phenotypes (in the FSQ/male $\times \mathrm{BKSQ} /$ female cross) or to a level somewhat less than intermediate (i.e the reciprocal cross showed some deviation towards the choice exhibited by the bank population). The $F_{1}$ of reciprocal crosses were indistinguishable (Table $4 \mathrm{~b}$, comparison 9) and thus there was no evidence for maternal effects. 
Table 4 Substrate selection of the $\mathrm{F}_{1}$ and $\mathrm{F}_{2}$ generations of reciprocal laboratory crosses involving the Squamish Fucus (FSQ) and bank (BKSQ) populations with two different substrate choices: BK/F, bank and Fucus; BK/F( $\mathrm{H}_{2} \mathrm{~S}$ ), bank and Fucus with $\mathrm{H}_{2} \mathrm{~S}$ mud. Numbers in each substrate represent pooled replicates ( 100 amphipods per choice test). Replicates were judged homogeneous with the exception of the one experiment designated by $i$; substrate choice of the individual replicates in that case were: $40 / 57 \mathrm{~ns}, 56 / 42 \mathrm{~ns}, 59 / 38^{*}$. Wright's measure of departure from intermediacy was applied to incidences of Fucus choice. (b) Several comparisons of $\mathrm{BK} / \mathrm{F}$ and $\mathrm{BK} / \mathrm{F}\left(\mathrm{H}_{2} \mathrm{~S}\right)$ substrate selection between different $\mathrm{BKSQ}$ and $\mathrm{FSQ}$ laboratory hybrids using a contingency chi-square analysis. Males are listed first in each of the crosses compared

\begin{tabular}{|c|c|c|c|c|c|c|c|c|c|}
\hline \multirow{2}{*}{\multicolumn{2}{|c|}{$\begin{array}{l}\text { (a) } \\
\text { Parents }\end{array}$}} & \multicolumn{4}{|l|}{$F_{1}$} & \multicolumn{4}{|l|}{$\mathrm{F}_{2}$} \\
\hline & & \multicolumn{2}{|l|}{$\mathrm{BK} \& \mathrm{~F}$} & \multicolumn{2}{|l|}{$\mathrm{BK} \& \mathrm{~F}\left(\mathrm{H}_{2} \mathrm{~S}\right)$} & \multicolumn{2}{|l|}{$\mathrm{BK} \& \mathrm{~F}$} & \multicolumn{2}{|l|}{$\mathrm{BK} \& \mathrm{~F}\left(\mathrm{H}_{2} \mathrm{~S}\right)$} \\
\hline Male & Female & $\begin{array}{l}\text { Choice } \\
\text { BK/F }\end{array}$ & $\begin{array}{l}\text { Wright's } \\
\text { measure }\end{array}$ & $\begin{array}{l}\text { Choice } \\
\mathrm{BK} / \mathrm{F}\left(\mathrm{H}_{2} \mathrm{~S}\right)\end{array}$ & $\begin{array}{l}\text { Wright's } \\
\text { measure }\end{array}$ & $\begin{array}{l}\text { Choice } \\
\mathrm{BK} / \mathrm{F}\end{array}$ & $\begin{array}{l}\text { Wright's } \\
\text { measure }\end{array}$ & $\begin{array}{l}\text { Choice } \\
\mathrm{BK} / \mathrm{F}\left(\mathrm{H}_{2} \mathrm{~S}\right)\end{array}$ & $\begin{array}{l}\text { Wright's } \\
\text { measure }\end{array}$ \\
\hline BKSQ & BKSQ & $155 / 137$ & 0.00 & $231 / 69^{* * *}$ & 0.00 & $106 / 90 \mathrm{~ns}$ & 0.00 & $207 / 75^{* * *}$ & 0.00 \\
\hline BKSQ & FSQ & $66 / 225^{* * *}$ & 0.74 & $100 / 189^{* * *}$ & 0.71 & $131 / 166^{*}$ & 0.28 & $165 / 127 *$ & 0.27 \\
\hline FSQ & BKSQ & $50 / 237^{* * *}$ & 0.87 & $82 / 204^{* * *}$ & 0.81 & $122 / 173^{* *}$ & 0.35 & $132 / 155 \mathrm{~ns}$ & 0.44 \\
\hline FSQ & FSQ & $35 / 255^{* * *}$ & 1.00 & $50 / 234^{* * *}$ & 1.00 & $53 / 241^{* * *}$ & 1.00 & $33 / 259^{* * *}$ & 1.00 \\
\hline
\end{tabular}

(b)

Contingency chi-square

\begin{tabular}{lcc} 
Experiments compared & $\mathrm{BK} \& \mathrm{~F}$ & $\mathrm{BK} \& \mathrm{~F}\left(\mathrm{H}_{2} \mathrm{~S}\right)$ \\
\hline 1. $\mathrm{BKSQ} \times \mathrm{BKSQ}\left(\mathrm{F}_{1}\right)$ vs. $\mathrm{BKSQ} \times \mathrm{FSQ}\left(\mathrm{F}_{1}\right)$ & $55.95^{* * *}$ & $105.78^{* * *}$ \\
2. $\mathrm{BKSQ} \times \mathrm{BKSQ}\left(\mathrm{F}_{1}\right)$ vs. $\mathrm{FSQ} \times \mathrm{BKSQ}\left(\mathrm{F}_{1}\right)$ & $78.93^{* * *}$ & $135.50^{* * *}$ \\
3. $\mathrm{BKSQ} \times \mathrm{FSQ}\left(\mathrm{F}_{1}\right)$ vs. FSQ $\times \mathrm{FSQ}\left(\mathrm{F}_{1}\right)$ & $10.66^{* *}$ & $20.54^{* * *}$ \\
4. $\mathrm{FSQ} \times \mathrm{BKSQ}\left(\mathrm{F}_{1}\right)$ vs. FSQ $\times \mathrm{FSQ}\left(\mathrm{F}_{1}\right)$ & $2.17 \mathrm{~ns}$ & $9.19^{* *}$ \\
5. $\mathrm{BKSQ} \times \mathrm{FSQ}\left(\mathrm{F}_{1}\right)$ vs. $\mathrm{BKSQ} \times \mathrm{FSQ}\left(\mathrm{F}_{2}\right)$ & $29.34^{* * *}$ & $27.22^{* * *}$ \\
6. $\mathrm{FSQ} \times \mathrm{BKSQ}\left(\mathrm{F}_{1}\right)$ vs. FSQ $\times \mathrm{BKSQ}\left(\mathrm{F}_{2}\right)$ & $38.89^{* * *}$ & $17.64^{* * *}$ \\
7. $\mathrm{FSQ} \times \mathrm{FSQ}\left(\mathrm{F}_{1}\right)$ vs. FSQ $\times \mathrm{FSQ}\left(\mathrm{F}_{2}\right)$ & $3.60 \mathrm{~ns}$ & $4.14^{*}$ \\
8. $\mathrm{BKSQ} \times \mathrm{BKSQ}\left(\mathrm{F}_{1}\right)$ vs. BKSQ $\times \mathrm{BKSQ}\left(\mathrm{F}_{2}\right)$ & $0.02 \mathrm{~ns}$ & $0.82 \mathrm{~ns}$ \\
9. $\mathrm{BKSQ} \times \mathrm{FSQ}\left(\mathrm{F}_{1}\right)$ vs. FSQ $\times \mathrm{BKSQ}\left(\mathrm{F}_{1}\right)$ & $2.17 \mathrm{~ns}$ & $2.07 \mathrm{~ns}$ \\
\hline
\end{tabular}

$*=0.01<P<0.05$

$* *=0.001<P<0.01$;

*** $=P<0.001$;

$\mathrm{ns}=$ not significant.

Control crosses showed no evidence for a significant drop in substrate choice in the $F_{2}$, indicating that this trend in interpopulation hybrids was not a sampling artifact (Table 4b, comparisons 7 and 8).

Crosses between Fucus and wood debris amphipods resulted in an $F_{1}$ and $F_{2}$ that showed no significant preference for either substrate (Table 5). Incidences of wood debris choice in the interpopulation hybrids were approximately intermediate between the parental phenotypes.

\section{Discussion}

Crosses between bank and wood debris amphipods showed a distinct deviation towards wood debris preference in the $F_{1}$, which was independent of the source of the mother, indicating that the choice was not a maternal effect. This preference for wood debris substrate completely disappeared in the $F_{2}$, falling to an approximately intermediate level, ruling out the possibility that the dominance deviation in the $F_{1}$ was due to a single dominant gene. Similar results were obtained in crosses involving Fucus and bank except that the dominance deviation was not so extreme. Crosses between Fucus and wood debris amphipods resulted in an $F_{1}$ and $F_{2}$ that were intermediate in their substrate choice. Without the results of the $B K \times W D$ and Fucus $\times$ BK crosses the intermediate result would have suggested additive genetic effects in wood debris and Fucus populations for their respective substrate choices. An interpretation more consistent with the overall results however, is that the effect of dominant loci in the Fucus and wood debris populations acting in opposite directions, was to cancel each other out (a 
Table 5 Substrate selection of the $F_{1}$ and $F_{2}$ generations of reciprocal laboratory crosses involving the Squamish Fucus (FSQ) and wood debris (WDSQ) populations. Numbers in each substrate $(\mathrm{F}=$ Fucus, WD $=$ wood debris $)$ represent pooled replicates (100 amphipods per choice test). Replicates were judged homogeneous with the exception of the one experiment designated by $i$; substrate choice of the individual replicates in that case were: $40 / 59 \mathrm{~ns}, 60 / 39^{*}, 48 / 52 \mathrm{~ns}$. Wright's measure of departure from intermediacy was applied to incidences of wood debris choice

\begin{tabular}{|c|c|c|c|c|c|}
\hline \multicolumn{2}{|l|}{ Parents } & \multicolumn{2}{|l|}{$F_{1}$} & \multicolumn{2}{|l|}{$\mathrm{F}_{2}$} \\
\hline & & Choice & Wright's & Choice & Wright's \\
\hline Male & Female & F/WD & measure & F/WD & measure \\
\hline FSQ & FSQ & $172 / 25^{* * *}$ & 0.00 & $180 / 19^{* * *}$ & 0.00 \\
\hline FSQ & WDSQ & $132 / 158 \mathrm{~ns}$ & 0.59 & '1 $148 / 150$ & 0.52 \\
\hline WDSQ & FSQ & $133 / 167 \mathrm{~ns}$ & 0.61 & $163 / 130 \mathrm{~ns}$ & 0.44 \\
\hline WDSQ & WDSQ & $34 / 166^{* * *}$ & 1.00 & $23 / 175^{* * *}$ & 1.00 \\
\hline
\end{tabular}

$*=0.01<P<0.05$;

$* * *=P<0.001$;

$\mathrm{ns}=$ not significant.

result predicted by quantitative genetic theory, see Falconer, 1981). The results of all the crosses are consistent with an interpretation of polygenic control with dominant genetic effects in wood debris and Fucus populations for their respective substrate choices (Falconer, 1981). Leslie \& Dingle (1983) and Jaenike (1987), in studies of oviposition preference in two species of phytophagous insects, have reported similar evidence for polygenic control with dominant genetic effects in some populations or strains.

The dominant genetic effects are likely to be a consequence of how these populations arose. An aerial photograph of the Squamish estuary from 1932 clearly shows that there was log storage at that time in the present wood debris habitat. Log handling activities first started in the area around the turn of the century. All available evidence indicates that prior to $\log$ storage in Squamish, this area was a bank habitat. Remnant patches of Carex (including the embankment that forms the perimeter of such a marsh) are present in this log storage area and Carex rhizomes are present all across the mud flat (top of the old marsh), at anywhere from 2 to $25 \mathrm{~cm}$ below the surface. This means that a wood debris habitat in this estuary has existed for approximately 75 years (time for 150 generations) and was once a bank habitat. As other bank habitats, both within this estuary and in other estuaries, support populations of E. confervicolus (Levings et al., 1975; Pomeroy \& Levings, 1980; Stanhope, 1989), it is likely that the creation of the log debris habitat in this location was an environmental perturbation of an already existing bank population, which resulted in a change in the population trait distribution towards wood debris preference. This is one of the basic means of detecting natural selection in wild populations outlined by Endler (1986). Furthermore, a genotype analysis (genomic DNA RFLP) of these three populations, as well as six additional populations occupying the same three habitat types, from geographically proximal and removed locations, has indicated that the Squamish bank and wood debris populations have the most similar genotypes (Stanhope, 1989). Several RFLP were identified which were common only to the Squamish bank and wood debris populations. The ancestor of the Squamish wood debris population was therefore, in all probability, a bank population. In most cases reported to be examples of sympatric diversification due to shifts in host or habitat preference, it is not known whether the colonization event represented the invasion or development of a new resource or simply the expansion of an old one. In our case the evidence strongly suggests that the wood debris population arose from a bank ancestor and that coincident with this was the development of a preference for a wood debris habitat. Thus, the dominant genetic effects in wood debris are probably a consequence of the manner in which the population arose. With the buildup of wood debris, strong natural selection may have greatly reduced the population size and genetic variation, leading to inbreeding. The resulting population would have considerably different gene frequencies from the ancestral bank population and thus crosses between wood debris and bank would be heterotic.

We have no similar indication of when or how the 
Fucus habitat arose; other estuaries of the north-east Pacific have similarly juxtaposed wood debris and Fucus habitats but there are also estuaries in which this type of Fucus habitat exists independent of an adjacent wood debris environment (Stanhope, 1989; M. J. Stanhope and C. D. Levings, unpublished data). The Fucus habitat may have existed prior to log storage or it may have arisen as a consequence of log storage. It is possible that intertidal log-handling activities resulted in the establishment of two new environments, generating the possibility of disruptive selection for habitat preference (superior fitness in the habitat of choice). Disruptive selection is a key feature of Rice's (1984) model of the role of habitat preference in the evolution of reproductive isolation. If disruptive selection on habitat preferences resulted in the present situation, then the genotype of the Fucus and wood debris populations should reflect their split from a common ancestor. The evidence, however, does not support this hypothesis; instead, the genotype of the Squamish Fucus population shows a much higher similarity to other Fucus populations than to the Squamish wood debris or bank populations (Stanhope, 1989). It appears more likely therefore, that, unlike the situation in the Squamish wood debris habitat, where wood debris substrate preference reflects a shift in habitat preference, Fucus substrate preference is a characteristic of a particular race of $E$. confervicolus and what we are observing is the outcome of a colonization event by members of that race.

Whatever the series of events leading to the present genetic differences in amphipod habitat preferences, and whether or not there is a cause-effect relationship between the development of substrate preferences and the differentiation of these groups, it is clearly a contributing factor to the maintenance of a subdivided population structure in this estuary. The results of the crosses, as well as the earlier genotype analysis (Stanhope, 1989), indicate that the three sympatric populations in this study are genetically distinct. Although bank amphipods did not excercise a clear substrate choice, like the Fucus and wood debris amphipods, they did show a significant avoidance of wood debris substrate and the $\mathrm{H}_{2} \mathrm{~S}$ mud characteristic of the Fucus habitat. The cues bank amphipods were using to detect substrates appeared to be different from those of amphipods in the other two populations. They were the only group which behaved differently in tests with and without $\mathrm{H}_{2} \mathrm{~S}$ mud. All these substrate situations undoubtedly elicit different chemicals that the amphipods could be responding to. Hay et al. (1987) have shown that gammarid amphipods will make dramatically different food choices in response to structurally very similar algal metabolic compounds.
The modelling results of Diehl \& Bush (1989), Rice (1984) and the recent experimental work of Rice \& Salt (1990) suggest that considerable sympatric population divergence (and in fact significant progress towards sympatric speciation) can occur if mate choice is closely coupled with habitat preference. The fact that these populations are genetically distinct suggests that they are mating assortatively. A factor which contributes to assortative mating is the differences in reproductive cycle between the Fucus population and the other two. The Fucus population is univoltine and bank and wood debris populations are bivoltine (Stanhope \& Levings, 1985). Amphipods in bank and wood debris that are the result of a summer reproductive period reach reproductive maturity in early winter and interpopulation hybrids can be readily formed at this time (M. J. Stanhope, unpublished data). Amphipods released as part of the summer brood in Fucus delay reproductive maturity, have a longer life-span and do not reproduce until the following spring (Stanhope \& Levings, 1985; Stanhope, 1989), at which time it is possible to perform interpopulation crosses between all three populations using the single generation from Fucus and the members of the winter cohort from bank and wood debris. It is not uncommon for gammarid amphipod species that commonly occur together to have distinct and displaced reproductive periods (Kolding \& Fenchel, 1979), presumably an evolved means of preventing interspecific mating attempts. There were no difficulties in crossing the summer adults from bank and wood debris and the single generation from Fucus; possible postmating isolating mechanisms such as hybrid infertility or inviability appeared to be absent (we emphasize, however, that we have not actually tested for this, i.e. measurements of interpopulation mating success and hybrid fitness). This partial asynchrony in the reproductive cycle suggests that at certain times there are very marked fitness differences associated with choosing the 'wrong' habitat. For example, wood debris and bank amphipods that choose the Fucus habitat in the October to February period will find it difficult or impossible to find a mate. It appears, therefore, that habitat preference is just one of several precopulatory isolating mechanisms which contribute to the subdivided population structure in this estuary.

There have been other studies in which habitat preference has been implicated as an important factor in the differentiation of amphipod groups (see for example Fenchel \& Kolding, 1979; Kolding, 1981), while still other studies have demonstrated substantial levels of additive genetic variance for fitness components in natural populations (Doyle \& Hunte, 1981a, b). Goedmakers (1980) presents life-history 
evidence which suggests that microgeographic races of three gammarid amphipod species exist along the same river (some stations less than $1 \mathrm{~km}$ apart). We submit that microgeographic races of gammaridean amphipods may in fact be the norm rather than the exception and that an important factor in this race formation may be polygenic control of habitat choice. Genetic shifts in the habitat preference of marine crustaceans may occur rapidly enough to be of interest not only to evolutionary biologists, but also to marine ecologists concerned with physical alteration of nearshore and estuarine habitats. As Diehl \& Bush (1989) have suggested, the overall frequency of sympatric diversification events may be more limited by the stability of distinct habitats over time than by genetic constraints.

\section{Acknowledgements}

We would like to thank Dr C. D. Levings and the West Vancouver Laboratory for their generous provision of aquarium facilities. M. Connelly, J. Brown and F. Juanes offered much helpful advice. We appreciate the very constructive comments of an anonymous reviewer. M. Stanhope was supported by a GREAT award from the British Columbia Science Council.

\section{References}

BOROWSKY, в. 1984. The effects of receptive females' secretions on some male reproductive behaviors in the amphipod crustacean. Microdeutopus gryllotalpa. Mar. Biol., 84, 183-188.

BOROWSKY, B. 1985. The responses of males and females to each others' secretions in the amphipod crustacean Gammarus palustris. J. Chem. Ecol., 11, 1545-1552.

BOROWSKY, R., BOROWSKY, B., MILANI, H. AND GREENBERG, P. 1985. Amylase variation in the salt marsh amphipod, Gammarus palustris. Genetics, 111, 311-323.

BUSH, G. L. 1974. The mechanism of sympatric host race formation in the true fruit flies (Tephritidae). In: White, M. J. D. (ed.), Genetic Mechanisms of Speciation in Insects, Australia and New Zealand Book Co., Brookvales, NSW, Australia, pp. 3-23.

BUSH, G. L. 1987. Evolutionary behavior genetics. In: Huettel, M. D. (ed.), Evolutionary Genetics of Invertebrate Behavior, Plenum, New York, pp. 1-5.

CHRISTENSEN, B. 1977. Habitat preference among amylase genotypes in Asellus aquaticus (Isopoda, Crustacea). Hereditas, 87, 21-26.

DIEHL, S. R. AND BUSH, G. L. 1989. The role of habitat preference in adaptation and speciation. In: Otte, D. and Endler, J. A. (eds), Speciation and Its Consequences, Sinauer Associates, Sunderland, MA, pp. 345-365.

DOYLE, R. W. AND HUNTE, w. 1981a. Genetic changes in fitness and yield of a crustacean population in a controlled environment. J. Exp. Mar. Biol. Ecol., 52, 147-156.

DOYLE, R. W. AND HUNTE, w. 1981b. Demography of an estuarine amphipod (Gammarus lawrencianus) experimentally selected for high 'r': a model of the genetic effects of environmental change. Can. J. Fish. Aquat. Sci., 38, 1120-1127.

EDGAR, G. J. 1983. The ecology of south-east Tasmanian phytal animal communities. IV. Factors affecting the distribution of ampithoid amphipods among algae. J. Exp. Mar. Biol. Ecol., 70, 205-225.

Endler, J. A. 1986. Natural Selection in the Wild. Princeton University Press, Princeton.

FALCONER, D. S. 1981. Introduction to Quantitative Genetics. Longman, New York.

FELSENSTEIN, J. 1981. Skepticism towards Santa Rosalia, or why are there so few kinds of animals? Evolution, 35 , 124-138.

FENCHEL, T. M. AND KOLDING, s. 1979. Habitat selection and distribution patterns of five species of the amphipod genus Gammarus. Oikos, 33, 316-322.

FUTUYMA, D. J. 1987. The role of behavior in host associated divergence in herbivorous insects. In: Huettel, M. D. (ed.), Evolutionary Genetics of Invertebrate Behavior, Plenum, New York, pp. 295-302.

GOEDMAKERS, A. 1980. Microgeographic races of Gammarus fossarum Koch, 1836. Crustaceana, 6 (Suppl.), 216-224.

HAY, M. E., DUFFY, J. E. AND PFISTER, C. A. 1987. Chemical defense against different marine herbivores: are amphipods insect equivalents? Ecology, 68, 1567-1580.

JAENIKE, J. 1987. Genetics of oviposition-site preference in Drosophila tripunctata. Heredity, 59, 363-369.

KNEIB, R. T. 1982. Habitat preference, predation, and the intertidal distribution of gammaridean amphipods in a North Carolina salt marsh. J. Exp. Mar. Biol. Ecol., 59, 219-230.

KolDING, S. 1981. Habitat selection and life cycle characteristics of five species of the amphipod genus Gammarus in the Baltic. Oikos, 37, 173-178.

KOLDING, S. AND FENCHEL, T. M. 1979. Coexistence and life cycle characteristics of five species of the amphipod genus Gammarus. Oikos, 33, 323-327.

LESLIE, J. F. AND DINGLE, H. 1983. A genetic basis of oviposition preferences in the large milkweed bug, Oncopeltus fasciatus (Hemiptera: Lygaeidae). Ent. Exp. Appl., 34, 215-220.

LEVINGS, C. D., POMERoY, w. M. AND PRANGE, R. 1975. Sampling locations for intertidal biota and preliminary observations of habitats at some British Columbia estuaries. Fish. Res. Board Can. MS. Rep., 1345, 1-32.

MOORE, P. G. 1975. The role of habitat selection in determining the local distribution of animals in the sea. Mar. Behav. Physiol., 3, 97-100.

OAKDEN, J. M. 1984. Feeding and substrate preference in five species of phoxocephalid amphipods from central California. J. Crustac. Biol., 4, 233-247.

POMEROY, W. M. AND LEVINGS, C. D. 1980. Association and feeding relationships between Eogammarus ronfervicolus (Amphipoda, Gammaridae) and benthic algae on Sturgeon and Roberts Banks, Fraser River Estuary. Can.J. Fish. Aquat. Sci., 37, 1-10. 
RAUSHER, M. D. 1984. The evolution of habitat preference in subdivided populations. Evolution, 38, 596-608.

RICE, W. R. 1984. Disruptive selection on habitat preference and the evolution of reproductive isolation: A simulation study. Evolution, 38, 1251-1260.

RICE, W. R. AND SALT, G. W. 1990. The evolution of reproductive isolation as a correlated character under sympatric conditions: experimental evidence. Evolution, 44, 1140-1152.

RICKETTS, E. F., CALVIN, J., HEDGEPETH, J. M. AND PHILLIPS, D. W. 1985. Between Pacific Tides. Stanford University Press, Stanford.

SHARP, J. 1980. Culture studies on Eogammarus confervicolus (Amphipoda: Anisogammaridae). M.Sc. Thesis, University of British Columbia.

STANHOPE, M. J. 1989. Natural selection of life history traits in an estuarine amphipod. Ph.D. Thesis, Simon Fraser University.

STANHOPE, M. J. AND LEVINGS, C. D. 1985. Growth and production of Eogammarus confervicolus (Amphipoda: Anisogammaridae) at a log storage site and in areas of undisturbed habitat within the Squamish estuary, British Columbia. Can. J. Fish. Aquat. Sci., 42, 1733-1740.

STONER, A. W. 1980. Abundance, reproductive seasonality and habitat preferences of amphipod crustaceans in seagrass meadows of Apalachee Bay, Florida. Contr. Mar. Sci., 23, 63-77.

TAUBER, C. A. AND TAUBER, M. J. 1989. Sympatric speciation in insects: perception and perspective. In: Otte, D. and Endler, J. A. (eds), Speciation and Its Consequences, Sinauer Associates, Sunderland, MA. pp. 307-344.

VAN DOLAH, R. F. 1978. Factors regulating the distribution and population dynamics of the amphipod Gammarus palustris in an intertidal salt marsh community. Ecol. Monogr., 48, 191-217.

WRIGHT, s. 1978. Evolution and the Genetics of Populations, Vol. 4, Variability Within and Among Natural Populations. University of Chicago Press, Chicago.

ZAR, J. H. 1974. Biostatistical Analysis. Prentice-Hall, Inc., Englewood Cliffs, NJ. 